\title{
Ruptured primary ovarian pregnancy: a rare cause of haemoperitoneum - two case reports and review of literature
}

\author{
Renuka Malik*, Kavita Manchanda
}

Department of Obstetrics and Gynecology, Dr RML Hospital, New Delhi, India

Received: 06 April 2016

Revised: 07 May 2016

Accepted: 10 May 2016

\section{*Correspondence:}

Dr. Renuka Malik,

E-mail: renucam@yahoo.co.in

Copyright: (C) the author(s), publisher and licensee Medip Academy. This is an open-access article distributed under the terms of the Creative Commons Attribution Non-Commercial License, which permits unrestricted non-commercial use, distribution, and reproduction in any medium, provided the original work is properly cited.

\begin{abstract}
Primary ovarian ectopic pregnancy remains a rare type of ectopic pregnancy which is normally diagnosed at surgery. Preoperative diagnosis by ultrasound is difficult, though now is being reported. Intraoperative diagnosis of ovarian pregnancy is difficult, as it can be confused with bleeding corpus luteum. The etiology of ovarian pregnancy is unknown. Fertility treatments and intrauterine contraceptive devices remain important associated risk factors Medical management and laparoscopy in unruptured cases can conserve ovary but ruptured ectopic still report in causality of government hospital. Two case reports are discussed. Both patients presented with ruptured ovarian ectopic needing laparotomy. There was no history of IUCD use or fertility treatment in either of them. Preoperative ultrasound in both patients was suggestive of ruptured tubal ectopic. Both were only diagnosed intraoperatively and met speigelberg criteria. A review of the literature, the specific symptoms, diagnostic criteria, and treatment of primary ovarian ectopic is discussed. Ovarian conservation should remain the aim in ovarian ectopic. However, cases with advanced gestation with massive haemoperitoneum can make ovarian conservation difficult. Early diagnosis in unruptured ovarian ectopic can conserve ovary.
\end{abstract}

Keywords: Ovarian pregnancy, Speigelberg criteria, Haemoperitoneum

\section{INTRODUCTION}

Primary ovarian ectopic pregnancy is a rare entity. ${ }^{1,2}$ An ectopic pregnancy is characterized by implantation and development of an embryo outside of the uterine cavity, fallopian tube or in the ovary. The preoperative diagnosis of primary ovarian pregnancy is not easy. It is characterized by a poor clinical symptomatology and a difficult ultrasound diagnosis. The surgical criteria remain hard to prove. The confirmatory speigelberg criteria are possible only after surgery and pathology evaluation. Here we discuss two cases of ruptured ovarian pregnancy with haemoperitoneum presenting in casualty of a government hospital and review of the literature for the symptoms, diagnostic criteria, and treatment.

\section{CASE REPORT}

\section{Case 1}

28yrs old, Para 3 ,reported in casualty of Dr RML Hospital, New Delhi on 10/2/2016 with complaints of acute pain abdomen and multiple episodes of vomiting since one day. There was no history of amenorrhea but the flow was scanty in last cycle, 3 days back. There was no history of any contraceptive use. On examination, patient was pale, with pulse 110/min, B.P. 100/60mm Hg. There was distension and tenderness in lower abdomen. On per vaginum examination, cervical movements were tender and but no definite mass could be palpated. UPT was done and was found positive. USG abdomen showed ill-defined echogenic $5 \times 4 \mathrm{~cm}$ lesion in right adnexa alongwith free fluid in abdomen, with diagnosis of ruptured ectopic with hemoperitoneum. Other blood investigations 
were normal except $\mathrm{Hb}$ reported as $7.8 \mathrm{gm} / \mathrm{dl}$ On the basis of clinical and radiological findings a decision for urgent laparotomy was taken. At laparotomy, there was blood about 1.5litre, B/L fallopian tubes were normal but right ovary showed a small $0.5 \times 0.5 \mathrm{~cm}$ bleeding surface (Figure 1a), wedge resection of the bleeding structure was done thinking about the possibility of primary ovarian pregnancy or bleeding corpus luteum.. As patient was Para 3, bilateral tubal ligation was done. Dilation and curettage were also done thinking of possibility of bleeding corpus luteum. Histopathological report showed numerous villi with tiny focus of compressed ovarian tissue at periphery were reported as ovarian ectopic pregnancy (Figure 1b). Endometrial tissue showed secretory endometrium. Thus, intra-operative findings and histopathological report fulfilled Spigelberg criteria for ovarian pregnancy.

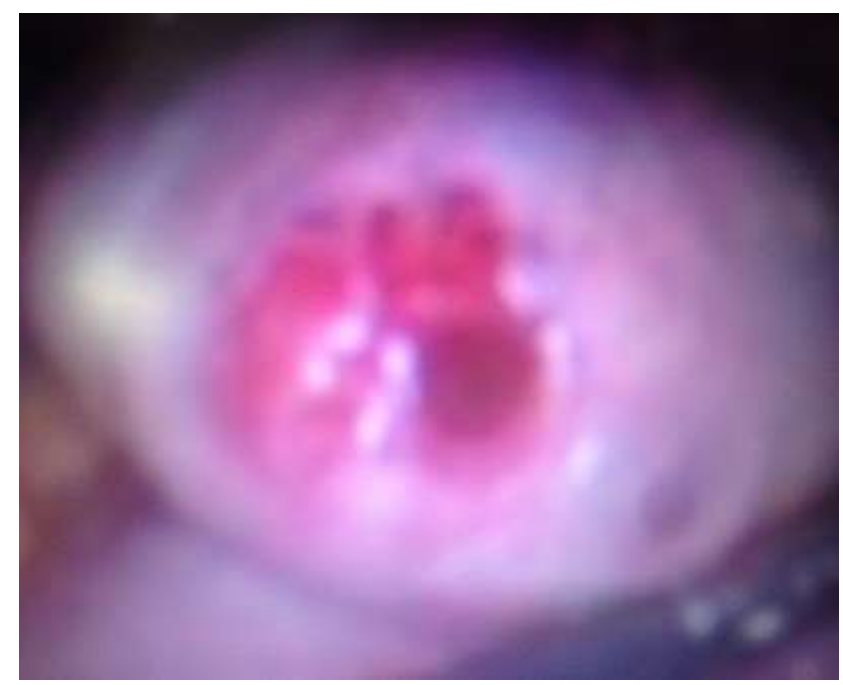

Figure 1A: Ovary with $0.5 \times 0.5 \mathrm{~cm}$ oozing area.

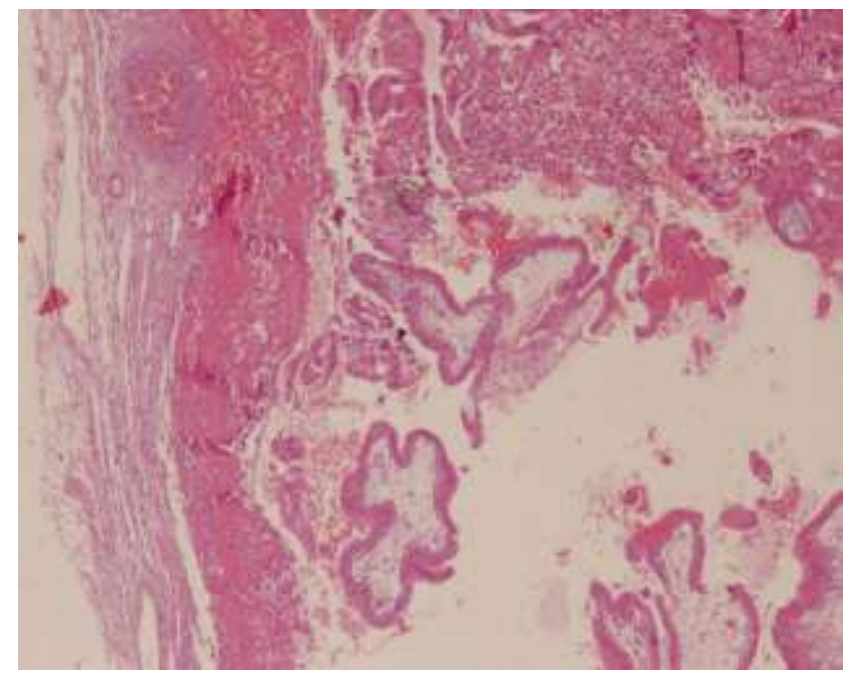

Figure 1B: Histopathological report with villi in ovarian stroma.

\section{Case 2}

A 20 year old, unmarried girl, educated computer graduate reported on 14/7/2015 in causality of Dr RML Hospital with pain lower abdomen for 2 days. She was sexually active and overdue by 17 days on the day of reporting to hospital. On further questioning, she gave history of doing a pregnancy test 10 days back herself which was positive and she took some abortifacient from chemist presumably MTP Pill. She had some spotting for 2-3 days after this. She denied any surgical intervention. She gave history of using emergency contraception 4 times in last 1year. On Examination-She appeared pale with clinical $\mathrm{Hb} \sim 7 \%$. Her pulse was 114 per min and BP 90/60 $\mathrm{mm} \mathrm{Hg}$. With consent $\mathrm{p} / \mathrm{s}$ and $\mathrm{p} / \mathrm{v}$ were done, which revealed normal size uterus with right adenexal fullness and tender cervical movements. Repeat urine pregnancy test was positive and serum $\beta \mathrm{HCG}$ was sent the value of which was found to be 41,000 . Emergency haematological investigations were sent which were normal with $\mathrm{Hb}$ reported as $8.2 \mathrm{gm} / \mathrm{dl}$. Ultrasound showed a $3.8 \times 3.3 \mathrm{~cm}$ gestational sac in right adenexa with evidence of free fluid-suggestive of ruptured ectopic. On the basis of these findings, patient was taken up for laparotomy. At laparotomy, an about 1.5 litter of blood was present in peritoneum. Both tubes were normal looking. Right ovary was bleeding with clots present in POD and adherent to colon. On lifting up right ovary trophoblast like tissue was separated and was sent for HPE. As entire ovary was bleeding profusely (Figure 2A, B), decision of oophorectomy while preserving normal fallopian tube was taken. Right Ovary and the trophoblast like structure over it were sent for HPE. Patient was transfused 2 units of blood. Post operatively the patient did well and was discharged on day 4 with stitch removal on day 8 from OPD.HPE report showed ovarian parenchyma with chorionic villi and corpus luteal cyst in ovary. The avulsed tissue sent showed chorionic villi and histopathology of ovary confirmed the presence of ovarian ectopic (Figure 2C).

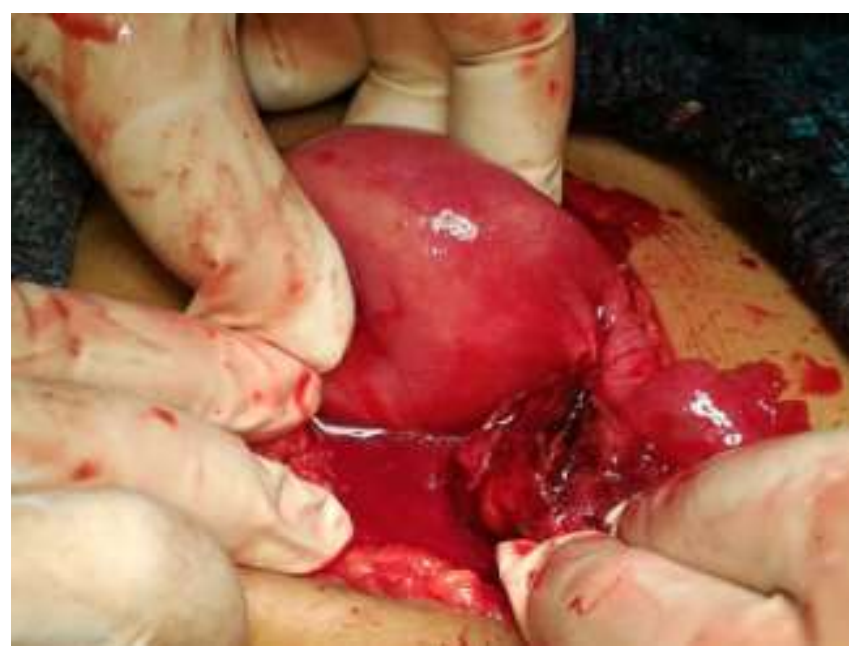

Figure 2A: Ruptured ovary with normal fallopian tube. 


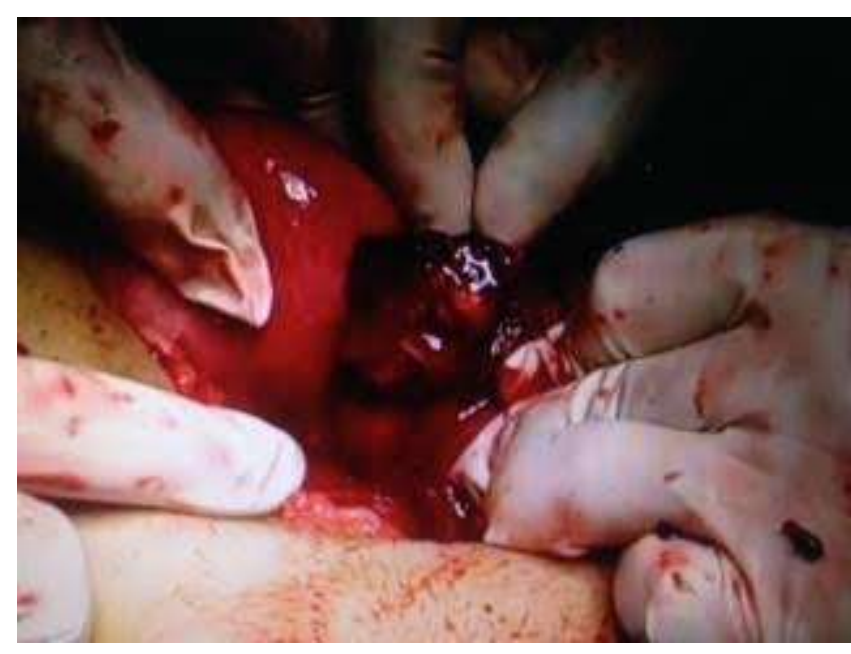

Figure 2B: Unsalvageable ovary.

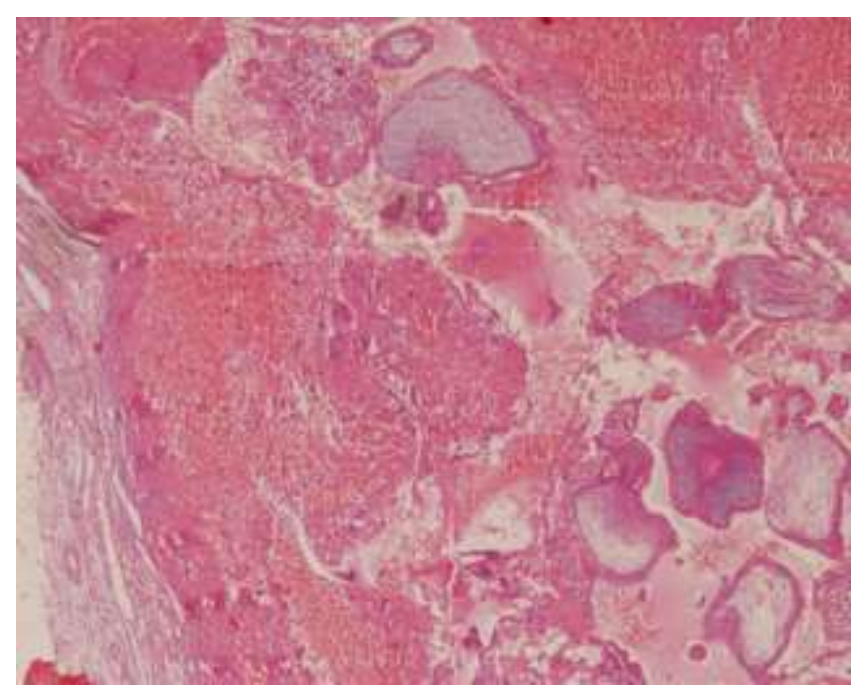

Figure 2C: HPE showing villi in ovarian stroma.

\section{DISCUSSION}

Primary ovarian pregnancy is one of the rarest types of extra uterine pregnancy. The first case was reported by St. Maurice. ${ }^{1}$ The first reported case of ovarian pregnancy was described by Monnissey S in $17^{\text {th }}$ Century. Primary ovarian pregnancy is even rarer accounting for $0.15-3 \%$ of all ectopic gestations. ${ }^{2}$ It can be primary when fertilization takes place with ovum still within the follicle or secondary when conceptous is expelled after fertilization in tube to implant within ovarian stroma. They can be intrafollicular or extrafollicular. Intrafollicular is invariably primary and extra follicular may be primary or secondary where ovarian tissue is usually absent in the gestational sac. Extra follicular are further classified as juxtafollicular, Juxta cortical, and interstitial pregnancy. Histology alone can confirm the diagnosis and distinguish the four sub types ${ }^{2}$. Criteria for ovarian pregnancy diagnosis is described in 1878 by Spiegelberg (i) the fallopian tube on the effected side must be intact; (ii) the gestational sac must occupy the normal position of the ovary; (iii) the ovary must be connected to the uterus by the ovarian ligament; and (iv) ovarian tissue must be located in the sac wall. Clinicians using methotrexate successfully in unruptured ovarian pregnancy, ask for a need for ultrasonic criteria of confirmation of primary ovarian pregnancy, as speigelberg criteria cannot be met. ${ }^{3}$ Unlike tubal ectopic, there is no association seen with PID in primary ovarian ectopic. Recent intrauterine contraceptive device usage has been found to be associated in proportions ranging from 57-90\%. ${ }^{4,5}$ Ectopic pregnancy is also a well-known complication after IVF and embryo transfer. ${ }^{6}$ However, in both our cases there was neither IUCD use nor any fertility treatment Ovarian pregnancy may be subclinical or may present with acute abdomen. Correct preoperative diagnosis requires high index of clinical suspicion which can be confirmed by ultrasonography and serum $\beta \mathrm{HCG}$ assay.

Ovarian pregnancy ends with rupture before the end of the first trimester. The clinical presentation usually resembles that of disturbed tubal ectopic pregnancy. The most common presenting symptoms include abdominal pain, vaginal bleeding, amenorrhea and palpable adnexal mass, not unlike other ectopic gestations, although patient may present with the sole complaint of pelvic pain, as in our two cases. Therefore, a differential diagnosis must be considered with tubal pregnancy, ruptured haemorrhagic corpus luteum, luteal cyst or chocolate cyst.

The diagnosis can sometimes be made before rupture by high resolution trans-vaginal ultrasonography. The diagnosis can be established sonographically by a hyper dense chorial ring which moves with the movement of ovary. The echogenicity of the ring is usually greater than the ovary itself. 3D ultrasound with Doppler aid in the diagnosis as the lesion is heterogeneous with mixed echoes and it mimics corpus luteum or a haemorrhagic cyst of ovary. A small mass compatible with 'bagel' appearance bulging from the cortex is suggestive of primary ovarian pregnancy. ${ }^{7}$

Medical management with methotrexate can be done in early and unruptured cases but diagnosis of ovarian pregnancy would remain doubtful. ${ }^{8}$ Surgical management is required in cases of ruptured ectopic which can be done either by laparoscopy or laparotomy. Laparoscopy can also aid in diagnosis with additional advantage of treating the same in haemodynamically stable patients. ${ }^{9}$ Decision for oophorectomy, salpingo-oophrectomy or ovarian preservation surgery depends upon extent of damage to tissue at laparoscopy or laparotomy. ${ }^{9-12}$ Conservative management with an ovarian pregnancy have a good prognosis for future fertility and therefore conservative surgical management with wedge resection is advocated. In rare cases, as in our case 2, oophorectomy may be necessary. This can happen if pregnancy is more advanced, which was probably the reason why the entire ovary was unsalvageable. 


\section{CONCLUSION}

Primary ovarian pregnancy is a rare entity. The diagnostic difficulty can be overcomed by high index of suspicion and with the use of advanced radiological techniques. High index of suspicion and early diagnosis is mainstay of treatment with good future fertility outcome although late cases with rupture will continue to report in hospitals, an attempt to diagnose through ultrasound and laparoscopy should be done in haemodynamically stable patients, with ovarian conservation.

Written consent taken from patient for publication of case with images.

Funding: No funding sources

Conflict of interest: None declared

Ethical approval: Not required

\section{REFERENCES}

1. Hertig AT. Discussion of GerinLojoie L. Ovarian pregnancy. Am J Obstet and Gynecol. 1951;62:920.

2. Das S, Kalyani R, Lakshmi V, Harendra Kumar ML. Ovarian pregnancy. Indian J Pathol Microbiol Microbiol. 2008;51(1):37-8.

3. Di Luigi G, Patacchiola F. Early ovarian pregnancy diagnosed by ultrasound and successfully treated with multidose methotrexate. A case report. clinExp obstet Gynecol. 2012;39(3):390-3.

4. Ercal T, Cinar O, Mumcu A, Lacin S, Ozer E. Ovarian pregnancy; relationship to an intrauterine device. Aust N Z J Obstet Gynaecol. 1997;37:362-4.

5. Razeizl A, Golan A, Pansky M. Ovarian pregnancy: a report of twenty cases in an institution. Am J Obstet Gynecol. 1990;163:1182-5.

6. Marcus SF, Brinsden PR. Primary ovarian pregnancy after in vitro fertilization and embryo transfer: report of seven cases. Fertility and Sterility. 1993;60(1):167-9.

7. Ghi T, Banfi A, Marconi R. Three-dimensional sonographic diagnosis of ovarian pregnancy Ultrasound Obstet Gynecol. 2005;26:102-4.

8. Shamma FN, Schwartz LB. Primary ovarian pregnancy successfully treated with methotrexate. Am J Obstet Gynecol. 1992;167:1307-10.

9. Einenkel J, Baier D. Laparoscopic therapy of an intact primary ovarian pregnancy with ovarian hyperstimulation syndrome: Case report. Hum. Reprod. 2000;15(9):2037-40.

10. Joseph RJ, Irvine LM. Ovarian ectopic pregnancy: aetiology, diagnosis, and challenges in surgical management. Obstet Gynaecol. 2012;32(5):472-4.

11. Scutiero G, Di Gioia P Primary ovarian pregnancy and its management. JSLS. 2012;16(3):492-4.

12. Melcer $\mathrm{Y}$, Smorgick $\mathrm{N}$ et al Primary Ovarian Pregnancy: 43 Years' Experience in a Single Institute and still a Medical Challenge. Isr Med Assoc J. 2015;17(11):687-90.

Cite this article as: Malik R, Manchanda K. Ruptured primary ovarian pregnancy: a rare cause of haemoperitoneum - two case reports and review of literature. Int J Reprod Contracept Obstet Gynecol 2016;5:2043-6. 